\title{
Effect of Health Care Provider Delays on Short-Term Outcomes in Patients With Colorectal Cancer: Multicenter Population-Based Observational Study
}

\author{
Ahmed Abdulaal, BSc, MBBS; Chanpreet Arhi, MRCS; Paul Ziprin, MB BCh, MD, FRCS
}

Imperial College London, London, United Kingdom

\section{Corresponding Author:}

Ahmed Abdulaal, BSc, MBBS

Imperial College London

Department of Surgery and Cancer, St Mary's Hospital Campus, Praed Street

London, W2 $1 \mathrm{NY}$

United Kingdom

Phone: 440754513315

Email: ahmed.abdulaal@nhs.net

\begin{abstract}
Background: The United Kingdom has lower survival figures for all types of cancers compared to many European countries despite similar national expenditures on health. This discrepancy may be linked to long diagnostic and treatment delays.

Objective: The aim of this study was to determine whether delays experienced by patients with colorectal cancer (CRC) affect their survival.

Methods: This observational study utilized the Somerset Cancer Register to identify patients with CRC who were diagnosed on the basis of positive histology findings. The effects of diagnostic and treatment delays and their subdivisions on outcomes were investigated using Cox proportional hazards regression. Kaplan-Meier plots were used to illustrate group differences.

Results: A total of 648 patients (375 males, 57.9\% males) were included in this study. We found that neither diagnostic delay nor treatment delay had an effect on the overall survival in patients with $\mathrm{CRC}\left(\chi_{3}^{2}=1.5, P=.68 ; \chi 23=0.6, P=.90\right.$, respectively). Similarly, treatment delays did not affect the outcomes in patients with $\mathrm{CRC}\left(\chi_{3}^{2}=5.5, P=.14\right)$. The initial Cox regression analysis showed that patients with CRC who had short diagnostic delays were less likely to die than those experiencing long delays (hazard ratio $0.165,95 \%$ CI $0.044-0.616 ; P=.007)$. However, this result was nonsignificant following sensitivity analysis.

Conclusions: Diagnostic and treatment delays had no effect on the survival of this cohort of patients with CRC. The utility of the 2-week wait referral system is therefore questioned. Timely screening with subsequent early referral and access to diagnostics may have a more beneficial effect.
\end{abstract}

(Interact J Med Res 2020;9(3):e15911) doi: 10.2196/15911

\section{KEYWORDS}

surgery; cancer; colorectal; delay

\section{Introduction}

Colorectal cancer $(\mathrm{CRC})$ is the second most common cause of cancer-related deaths in the United Kingdom, and it accounted for 42,000 cases of cancer diagnoses in 2018 [1]. In fact, the United Kingdom has lower survival figures for all types of cancers than many European countries despite similar national expenditures on health [2]. The EUROCARE-4 study demonstrated that age-adjusted 5-year CRC mortality in the United Kingdom is significantly higher than that in the Nordic countries and Central Europe [2]. Abdel-Rahman et al [3] found that CRC accounted for the largest number of avoidable cancer-related deaths in the United Kingdom, with approximately 4090 avoidable cases.

Although surgery with curative intent is the preferred treatment modality for CRC [4], Gatta et al [5] found that only a small proportion of patients had undergone an elective procedure in the United Kingdom, usually owing to the advanced stage of cancer at diagnosis. A large proportion of patients with CRC are admitted as emergencies in the United Kingdom [6]. Emergency patients have a 1-year mortality that is $\geq 25 \%$ higher than patients who present through the screening and elective 
pathways [7]. The variability in the CRC survival is the greatest in the first year following diagnosis [8]; therefore, emergency patients may account in part for the higher 1-year mortality risk in the United Kingdom.

Thomson and Forman [9] demonstrated that patients with breast cancer who survive up to 1 year are more likely to survive up to 5 years. However, CRC is more complicated, as the 5-year conditional survival remains significantly worse for this cancer type [9]. This suggests that systematic delays such as delays in the referral, diagnosis, and treatment could have a constitutive effect on the long-term outcomes in patients in the United Kingdom and Europe [9]. Therefore, identifying and reducing the delays may lead to the detection of CRC at an early stage and diminish the proportion of emergency presentations, thereby eradicating the survival gap.

Previous studies have shown mixed results, while some studies have found no association [10], negative association [11], or "U-shaped" association [12] between delay and survival in patients with CRC. Many studies focus solely on the diagnostic interval [13] or consider general delays [14]. The aim of this study was to investigate the effect of diagnostic and treatment delays and their subdivisions on the survival of patients with CRC. We aimed to identify whether health care provider delays seen in the Imperial College Healthcare National Health Service Trust are related to the survival of patients with CRC. The hypothesis was that delays were associated with an increased risk of death.

\section{Methods}

\section{Data Sources}

Data were obtained from the Somerset Cancer Register, which is a database that collects wait times and outcomes data in line with the national database requirements [15]. Dataset collection was performed from January 2013 to March 2016.

\section{Study Population}

A total of 5456 patients were investigated for CRC. Patients not diagnosed with $\mathrm{CRC}$ were excluded $(\mathrm{n}=4386)$. To ensure database validity, the patients' sources of referral were examined. Of the excluded patients, 4118 (93.9\%) patients within the first exclusion were referred through the 2-week wait pathway. In the United Kingdom, a 2-week wait referral is an urgent referral made by a patient's general practitioner, wherein the patient should be seen within a 14-day period by a secondary care specialist. Such a referral should be made when a patient presents with symptoms that may indicate cancer. Of the 4118 patients with CRC, 246 were diagnosed through the 2-week wait pathway, representing a $5.9 \%$ conversion rate. This is in line with the $5.4 \%$ conversion rate that was reported for bowel cancer observed at the national level [16]. Patients whose date of diagnosis did not reflect a positive histology finding were excluded (Table 1, $n=160$ ). These groups were excluded owing to uncertain diagnoses. Utilizing the date of positive histology results as the date of diagnosis has been employed by another study [12].

Patients with comorbid conditions of the gastrointestinal tract were excluded. This included patients with metastases from other primary cancers $(n=11)$ or benign neoplasms $(n=75)$. Patients with metastasis to the gastrointestinal tract may experience shorter diagnostic delays as a result of heightened physiological disturbance and yet exhibit worse outcomes [17], whereas those with benign neoplasms may exhibit a more insidious symptom development but a relatively favorable outcome [18,19]. Patients with inflammatory bowel disease were identified by searching multidisciplinary team reports for the following terms: colitis, proctitis, ulcerative, ulcerative colitis, Crohn(s), Crohn's, and inflammatory bowel disease. Those with inflammatory bowel disease were excluded $(n=7)$. Patients with inflammatory bowel disease represented $1.1 \%$ (7/648) of the cohort, which is in line with the expected prevalence of 1\%-2\% observed in all patients with CRC [20]. Patients who were referred following an emergency admission $(n=105)$ were excluded. Emergency presentations typically experience shorter delays and worse 1-year and 5-year outcomes [7,21], which may produce a misleading negative association between the delay and the survival [22]. Patients diagnosed with malignancies of the small intestine, anus, or anal canal were excluded $(n=64)$. The algorithm for patient inclusion is illustrated in Figure 1.

Table 1. Patient groups that were not diagnosed with colorectal cancer following a positive histology finding of a primary colorectal tumor ( $\mathrm{n}=160$ ).

\begin{tabular}{ll}
\hline Category of patients excluded & Patients, $\mathrm{n}(\%)$ \\
\hline A clinical diagnosis alone (patient symptomatology + a radiological investigation) & $138(86.2)$ \\
Diagnosis made after a positive serological tumor marker result & $1(0.6)$ \\
Unknown basis of diagnosis & $1(0.6)$ \\
Patients with an unrecorded basis of diagnosis & $20(12.5)$ \\
\hline
\end{tabular}


Figure 1. The algorithm used for patient inclusion. CRC: colorectal cancer; GI, gastrointestinal.

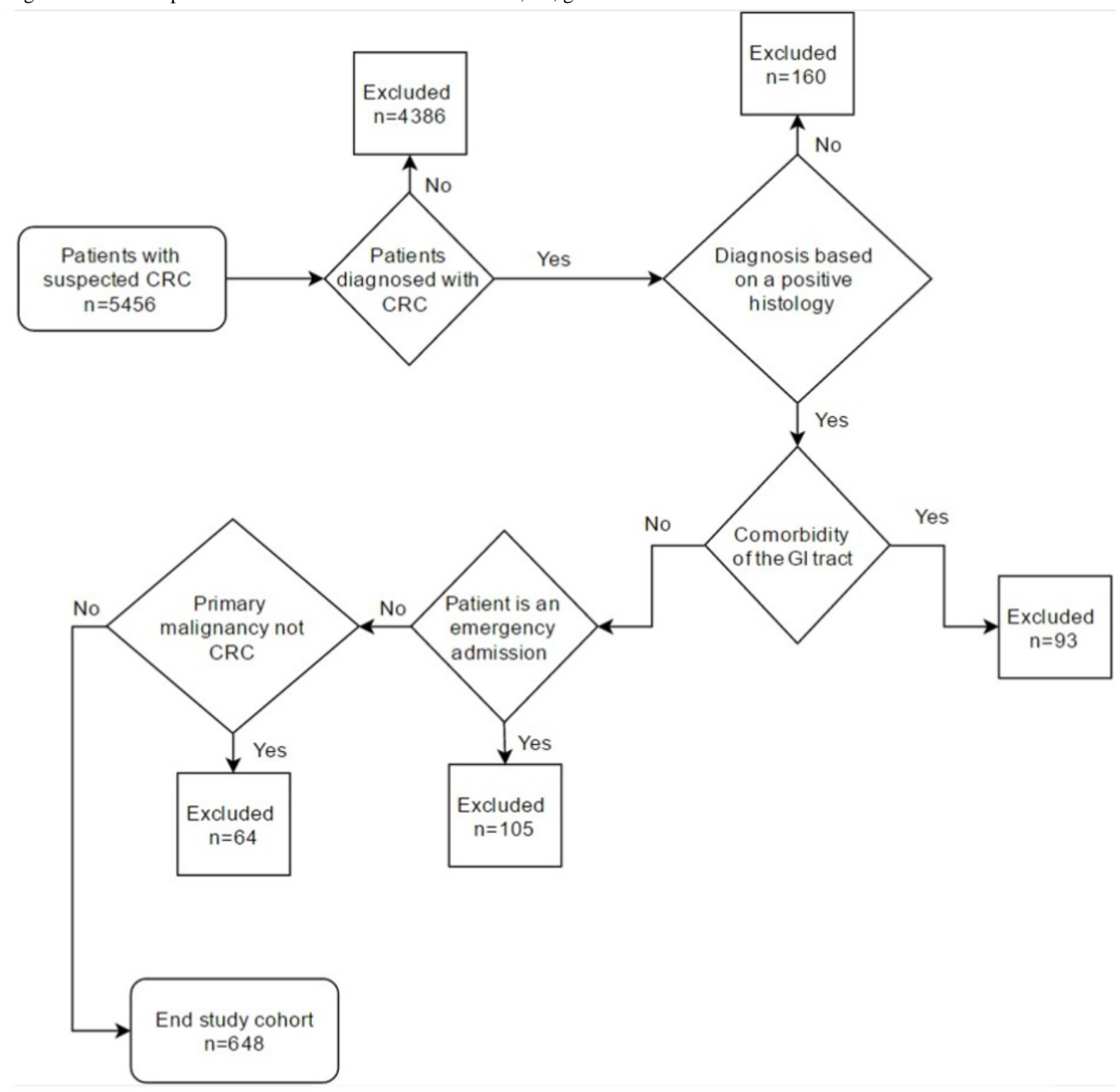

\section{Study Design}

This was a multicenter population-based observational study. When assessing survival, other studies have demonstrated different trends based on the cancer type [23,24], and therefore, colon and rectal cancer cohorts were considered independently.

\section{Lead Time Bias}

Patients included from the national bowel cancer screening program $(n=92)$ were particularly susceptible to lead time bias. This bias occurs when outcomes are measured following diagnoses that reflect different starting points along the natural history of a cancer [25,26]. This may lead to a statistical extension in survival length without an actual increase in the duration of life for the patients detected through screening programs [14,27]. In order to account for the lead time, a correction by Duffy et al [28] was used, which estimates the additional follow-up time owing to earlier cancer detection. It assumes an exponential distribution of the sojourn time (E[s]) [29] - the interval in which a cancer is asymptomatic but can be detected by screening and is defined as $\left.E(s)=\left(1-e^{(-\lambda t)}\right) / \lambda\right)$, where $t$ is the time at which a patient is last known to be alive and $\lambda$ is the transition rate from preclinical to clinical cancer [28]. The transition rate is calculated as $1 /$ mean sojourn time. Brenner et al [30] described age-specific and sex-specific estimates of the sojourn time for CRC. A weighted arithmetic mean sojourn time was calculated as 4.86 ; thus, $\lambda=0.21$. $E(\mathrm{~s})$ was subtracted from the observed survival time or time to the last known follow-up of patients referred through screening.

\section{Immortal Time Bias}

Patients receiving treatment for their CRCs were necessarily alive between receiving a diagnosis and initiating treatment. This period is described as an immortal time, wherein the study outcome cannot occur [31]. Such patients may therefore have an artificial increase in their survival time if it is measured from the date of diagnosis, and this would introduce bias when analyzing the effect of the treatment delays on the study outcomes [31,32]. To obviate this bias, survival was measured from the date of the first treatment when considering the effect of the treatment delays. Survival was measured from the date 
of diagnosis when considering the diagnostic delays and overall delays.

\section{Study Variables}

The effect of health care provider delay on survival was investigated. Survival was measured until death or censoring. Patients were censored at the last known live follow-up or at the end of the study period if no record of a follow-up is available; however, they were not recorded as deceased.

\section{Delay}

Delays were categorized into diagnostic and treatment delays. Delays and their subdivisions were analyzed separately as each delay type represents a discrete segment of the patient pathway [33]. Figure 2 illustrates all the delays considered in this analysis.

Figure 2. Representation of the delays and delay subdivisions considered for the analysis. T1: diagnostic delay; T1a: delay from referral based on symptoms to receipt of referral; T1b: referral delay; T1c: delay between hospital appointment and diagnosis; T2: treatment delay; T2a: delay between diagnosis and multidisciplinary team (MDT) meeting date; T2b: considered for those patients who received a surgical intervention; Ttotal: total delay from referral to surgery or treatment.



\section{Covariates}

The covariates considered in this study were related to the patient demographics, including age, gender, and ethnicity. The data of the location, histology, grade, and stage of the tumor were also included. Patient performance status, which reflects the functional status of the patients [34], was also considered. Covariates that succeed diagnosis but may confound treatment delay and survival included treatment modality, intent (as categorized by synchronous insertion into the Somerset Cancer Register database at the time of treatment), and setting. These covariates were therefore included in the treatment delay models.

\section{Statistical Analysis}

The median and IQR were calculated for diagnostic, referral, and treatment delays along with the delay quartiles. A survival analysis was conducted for all the delays and their subdivisions. Kaplan-Meier survival estimates were plotted for diagnostic and treatment delays by quartile. Group differences were analyzed using the log-rank test. The Cox proportional hazards regression analysis was used to investigate the effect of the covariates and to adjust for the confounding factors. To ensure the result validity, multiple sensitivity analyses were performed. Although deaths are regularly reported to the registry, diagnostic and treatment delay analyses were repeated for patients with a known live follow-up or death date. Next, all models were stratified by cancer stage, as stage may act as an intermediate factor between diagnostic delay and survival and it drives treatment regimens [14,23]. As suggested by previous researchers $[13,35]$, analyses of diagnostic delays were repeated after excluding the covariates of tumor stage and grade to account for any confounding created by including them in the primary model. A $P$ value of $\leq .05$ was considered statistically significant. SPSS statistics version 21 (IBM Corp) was used for the analysis.

\section{Results}

\section{Study Sample}

Of the 648 eligible patients, 375 were males (57.9\%) and 272 were females $(41.9 \%)$. Gender was not recorded for 1 patient $(0.1 \%)$. The mean age was 69 years (range 29-96 years; $95 \%$ CI 67.8-70.2). There were $243(37.5 \%)$ cases of rectal cancer and $405(62.5 \%)$ cases of colon cancers. Of the 243 patients with rectal cancer, $30(12.3 \%)$ died. Among the 405 patients with colon cancer, 38 (9.4\%) died. The mean follow-up period for the patients with a known live follow-up was 383 days $(95 \%$ CI 276.76-399.2). Patient characteristics are summarized in Table 2. 
Table 2. Patient characteristics by cancer type $(\mathrm{N}=648)$.

\begin{tabular}{|c|c|c|}
\hline Patient characteristics & Colon cancer cohort $(\mathrm{N}=405), \mathrm{n}(\%)$ & Rectal cancer cohort $(\mathrm{N}=243), \mathrm{n}(\%)$ \\
\hline \multicolumn{3}{|l|}{ Age (years) } \\
\hline$\leq 60$ & $92(22.7)$ & $53(21.8)$ \\
\hline $61-65$ & $52(12.8)$ & $32(13.2)$ \\
\hline $66-70$ & $52(12.8)$ & $48(19.8)$ \\
\hline $71-75$ & $57(14.1)$ & $46(18.9)$ \\
\hline $76-80$ & $65(16.0)$ & $30(12.3)$ \\
\hline $81-84$ & $51(12.6)$ & $12(4.9)$ \\
\hline$\geq 85$ & $36(8.8)$ & $22(9.1)$ \\
\hline \multicolumn{3}{|l|}{ Gender } \\
\hline Male & $229(56.6)$ & $146(60.1)$ \\
\hline Female & $176(43.4)$ & $96(39.5)$ \\
\hline Unknown gender & $0(0)$ & $1(0.4)$ \\
\hline \multicolumn{3}{|l|}{ Race/ethnicity } \\
\hline Caucasian & $173(42.7)$ & $104(42.8)$ \\
\hline Black & $25(6.2)$ & $8(3.3)$ \\
\hline Asian & $20(4.9)$ & $8(3.3)$ \\
\hline Mixed & $2(0.5)$ & $2(0.8)$ \\
\hline Other & $41(10.1)$ & $26(10.7)$ \\
\hline Unknown & $144(35.5)$ & $95(39.1)$ \\
\hline \multicolumn{3}{|l|}{ Cancer site $^{\mathbf{a}}$} \\
\hline Proximal colon & 169 (41.7) & $\mathrm{N} / \mathrm{A}^{\mathrm{b}}$ \\
\hline Transverse colon & $39(9.6)$ & N/A \\
\hline Distal colon & $186(45.9)$ & N/A \\
\hline Unspecified colon & $11(2.7)$ & N/A \\
\hline Rectosigmoid junction & N/A & $31(12.8)$ \\
\hline Rectum & N/A & $212(87.2)$ \\
\hline \multicolumn{3}{|l|}{ Cancer stage $^{c}$} \\
\hline I & $60(14.8)$ & $44(18.1)$ \\
\hline II & $65(16.0)$ & $43(17.7)$ \\
\hline III & $159(39.3)$ & $94(38.7)$ \\
\hline IV & $73(18.0)$ & $36(14.8)$ \\
\hline Unknown & $48(11.9)$ & $26(10.7)$ \\
\hline \multicolumn{3}{|l|}{ Histology } \\
\hline Adenocarcinoma & $364(89.9)$ & $208(85.6)$ \\
\hline Mucinous adenocarcinoma & $16(4.0)$ & $7(2.9)$ \\
\hline Signet ring cell carcinoma & $2(0.5)$ & $0(0)$ \\
\hline Neuroendocrine tumor & $4(1.0)$ & $3(1.2)$ \\
\hline Liposarcoma & $1(0.2)$ & $0(0)$ \\
\hline Other carcinoma & $11(2.7)$ & $14(5.8)$ \\
\hline Unknown histology & $7(1.7)$ & $11(4.5)$ \\
\hline Tumor differentiation & & \\
\hline
\end{tabular}




\begin{tabular}{|c|c|c|}
\hline Patient characteristics & Colon cancer cohort $(\mathrm{N}=405), \mathrm{n}(\%)$ & Rectal cancer cohort $(\mathrm{N}=243), \mathrm{n}(\%)$ \\
\hline Well differentiated (G1) & $7(1.7)$ & $3(1.2)$ \\
\hline Moderately differentiated (G2) & $264(65.2)$ & $162(66.6)$ \\
\hline Poorly differentiated (G3) & $87(21.5)$ & $41(16.9)$ \\
\hline Anaplastic (G4) & $1(0.2)$ & $1(0.4)$ \\
\hline Cannot be assessed (GX) & $6(1.5)$ & $5(2.1)$ \\
\hline Unknown differentiation & $40(9.9)$ & $31(12.8)$ \\
\hline \multicolumn{3}{|l|}{ Treatment type } \\
\hline Active monitoring & $4(1.0)$ & $10(0.4)$ \\
\hline Chemotherapy & $71(17.5)$ & $56(23.0)$ \\
\hline Palliative care & $15(3.7)$ & $7(2.9)$ \\
\hline Surgery & $292(72.1)$ & $140(57.6)$ \\
\hline Radiotherapy & $2(0.5)$ & $21(8.6)$ \\
\hline Unknown treatment & $21(5.2)$ & $18(7.4)$ \\
\hline \multicolumn{3}{|l|}{ Treatment intent } \\
\hline Adjuvant & $21(5.2)$ & $7(2.9)$ \\
\hline Curative & $268(66.2)$ & $128(52.6)$ \\
\hline Diagnostic & $6(1.5)$ & $5(2.1)$ \\
\hline Monitoring & $4(1.0)$ & $1(0.4)$ \\
\hline Neoadjuvant & $6(1.5)$ & $7(2.9)$ \\
\hline Palliative & $30(7.4)$ & $25(10.3)$ \\
\hline Radical/curative & $3(0.7)$ & $17(7.0)$ \\
\hline Unknown & $67(16.5)$ & $53(21.8)$ \\
\hline
\end{tabular}

${ }^{a}$ Proximal colorectal cancers are defined as cancers arising from the caecum up to and including the splenic flexure [36]. Cancers of the transverse colon are identified with the International Classification of Diseases for Oncology-10 code C184, which reflects "malignant neoplasms of the transverse colon." Distal cancers are those arising in the descending (C186) or sigmoid (C187) colon.

${ }^{\mathrm{b}}$ Not applicable.

${ }^{\mathrm{c}}$ Dukes' staging was reconciled with the TNM staging system as follows [37]: Dukes' A or TNM stage T1-T2, N0, M0 = Stage I; Dukes' B or TNM stage T3-T4, N0, M0 = Stage II; Dukes' C or TNM stage T any size, N1, M0 = Stage III; Any metastasis = Stage IV.

\section{Diagnostic Delays}

Diagnostic delays were calculated for $361(89.1 \%)$ of the 405 patients with colon cancer and $216(88.8 \%)$ of the 243 patients with rectal cancer. The median diagnostic delay was 34 days for both cancers (IQR 19-59 and 22-63 days, respectively). An analysis of the relationship between the cancer stage and diagnostic delay was performed. Diagnostic delays were right skewed and not normally distributed following the Kolmogorov-Smirnov test $(P=.04)$; therefore, a Kruskal-Wallis $\mathrm{H}$ test was utilized. There was no correlation between diagnostic delay and cancer stage in the patients with colon cancer $\left(\chi^{2}{ }_{4}=6.9\right.$, $P=.14)$ or rectal cancer $\left(\chi_{4}^{2}=4.7, P=.32\right)$.

\section{Referral Delay}

Referral delay was calculated for $390(96.3 \%)$ of the 405 patients with colon cancer and 238 (97.9\%) of the 243 patients with rectal cancer. The median referral delay was 10 days (IQR 4-15 days) for patients with colon cancer and 11 days (IQR 6-16 days) for patients with rectal cancer. The majority of the patients with colon cancer $(285 / 390,73.1 \%)$ and rectal cancer $(172 / 238$,
$72.3 \%$ ) experienced a referral delay of less than 2 weeks. However, $13.1 \%$ (51/390) of the patients with colon cancer and $13.4 \%(32 / 238)$ of the patients with rectal cancer experienced a referral delay of at least one month.

\section{Treatment Delays}

Treatment delays were calculated for 327 (80.1\%) of the 405 patients with colon cancer and $208(85.6 \%)$ of the 243 patients with rectal cancer. The median treatment delay was 31 days (IQR 19-55 days) for patients with colon cancer and 42 days (IQR 27-106 days) for patients with rectal cancer. In all, 16.5\% (54/327) of the patients with colon cancer and $11.5 \%$ (24/208) of the patients with rectal cancer experienced a treatment delay of $<2$ weeks. The majority of the patients with colon and rectal cancer experienced a treatment delay of $\geq 4$ weeks (168/327, $51.4 \%$ and $142 / 208,68.3 \%$, respectively). Treatment delays displayed a similar skewness to diagnostic delays and were not significantly associated with cancer stage in either patients with colon or patients with rectal cancer $\left(\chi_{4}^{2}=8.6, P=.07\right.$ and $\chi_{4}^{2}=9.4$, $P=.054$, respectively). 


\section{Colon Cancer Delay and Survival}

The log-rank test indicated no difference between long-term survival and diagnostic delay quartile (Figure $3, \chi_{3}^{2}=1.5, P=.68$ ). Diagnostic delay was a nonsignificant predictor of survival in the multivariate Cox regression model $(P=.23)$. Additionally, there was no significant relationship between treatment delay quartile and survival in the log-rank test (Figure $4, \chi_{3}^{2}=0.6$, $P=.90)$ or Cox regression model ( $P=.33)$. Tumor grade was an independent predictor of survival in both diagnostic and treatment delay models ( $P=.005$ and $P=.02$, respectively), as was the tumor stage $(P<.001$ for both models).

Figure 3. Kaplan-Meier plot illustrating the survival function by diagnostic delay quartile with time.

\section{Diagnostic delay}

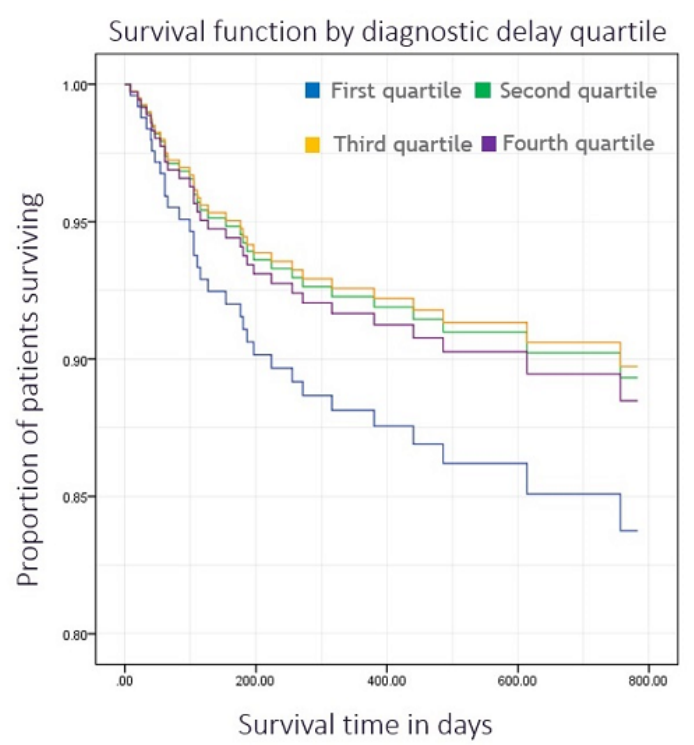

Figure 4. Kaplan-Meier plot illustrating the survival function by treatment delay quartile with time.

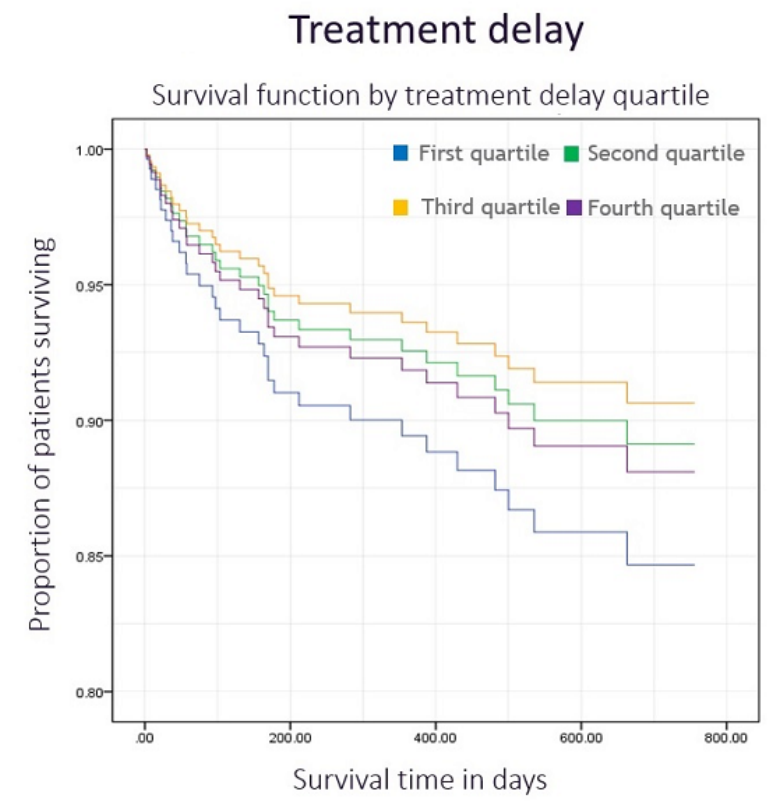

\section{Rectal Cancer Delays and Survival}

The relationship between diagnostic delay and survival in rectal cancer appears nonsignificant in the log-rank test $\left(\chi_{3}^{2}=5.5\right.$, $P=$.14). However, adjusting for covariates in the Cox regression model reveals a significant relationship between delay quartile and survival $(P=.03)$. Patients with the shortest delays were significantly less likely to die than those with the longest delays (hazard ratio $0.165,95 \%$ CI $0.044-0.616 ; P=.007$ ). Figure 5 illustrates these results. Tumor stage remained significant $(P=.04)$; however, tumor grade did not $(P=.06)$. Treatment delays did not affect survival in either the log-rank test $\left(\chi_{3}^{2}=0.1\right.$, $P=.99)$ or the Cox regression model $(P=.98)$. Figure 6 illustrates the survival function by treatment delay quartile. None of the covariates analyzed were significant in this model, except for tumor stage, which achieved a borderline result $(P=.053)$. 
Figure 5. Kaplan-Meier plot illustrating the survival function by diagnostic delay quartile with time.

\section{Diagnostic delay}

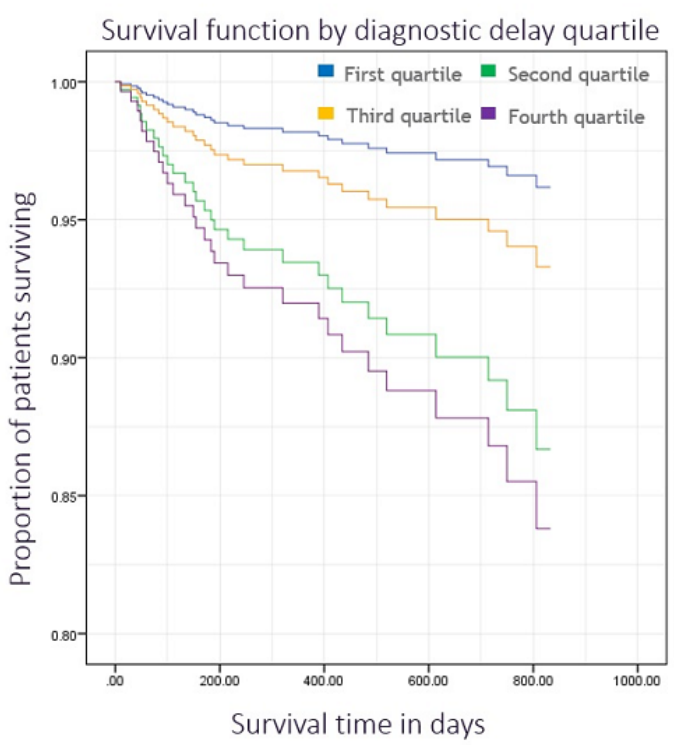

Figure 6. Kaplan-Meier plot illustrating the survival function by treatment delay quartile with time.

\section{Treatment delay}

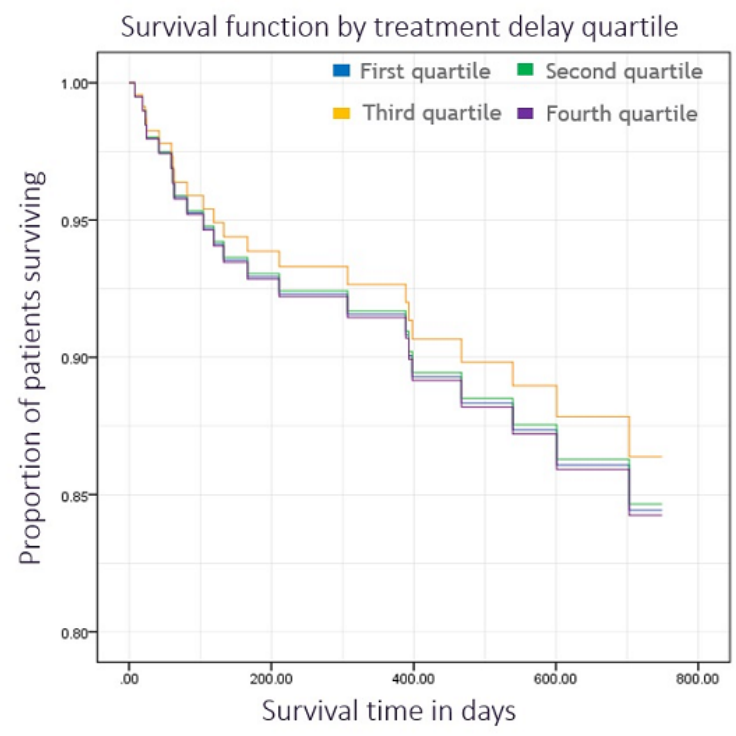

\section{Total Delay, Referral Delay, and Other Delay Subdivisions}

In the analysis of total delay, treatment modality, intent, and setting were not included as covariates. Total delays were not significantly related to survival in either patients with colon cancer $(P=.75)$ or in patients with rectal cancer $(P=.35)$. Similarly, referral delays did not affect survival in either patients with colon cancer or patients with rectal cancer $(P=.74$ and $P=.25$, respectively). A summary of the bias and covariate adjusted analyses is shown in Table 3. However, the delay between the first hospital appointment and the date of diagnosis significantly affected the survival in patients with rectal cancer (Figure 2). Patients with the shortest delays were significantly less likely to die than those with the longest delays (hazard ratio $0.325,95 \%$ CI $0.107-0.990 ; P=.048)$. 
Table 3. Patient numbers and significance values for total delay, referral delay, and delay subdivision analyses.

\begin{tabular}{|c|c|c|c|c|}
\hline \multirow[t]{2}{*}{ Delay } & \multicolumn{2}{|c|}{ Patients with colon cancer $(\mathrm{N}=405)$} & \multicolumn{2}{|c|}{ Patients with rectal cancer $(\mathrm{N}=243)$} \\
\hline & Patients, n (\%) & $P$ value & Patients, n (\%) & $P$ value \\
\hline $\mathrm{T} \mathrm{a}^{\mathrm{a}}$ & $399(98.5)$ & .12 & $243(100)$ & .64 \\
\hline $\mathrm{T} 1 \mathrm{~b}$ (referral delay) ${ }^{\mathrm{b}}$ & $390(96.3)$ & .74 & $237(97.5)$ & .25 \\
\hline $\mathrm{T} 1 \mathrm{c}^{\mathrm{c}}$ & $344(84.9)$ & .29 & $213(87.6)$ & .048 \\
\hline $\mathrm{T} 2 \mathrm{a}^{\mathrm{d}}$ & $298(73.5)$ & .56 & $187(76.9)$ & .25 \\
\hline $\mathrm{T} 2 \mathrm{~b}$ (surgical patients only) ${ }^{\mathrm{e}}$ & $237(58.5)$ & .89 & $128(52.7)$ & .69 \\
\hline Ttotal (total delay) ${ }^{\mathrm{f}}$ & $375(92.6)$ & .75 & $222(91.3)$ & .35 \\
\hline
\end{tabular}

${ }^{a}$ Delay between referral for symptoms and receipt of the referral by the hospital.

${ }^{\mathrm{b}}$ Delay between referral based on symptoms and date of hospital appointment (referral delay).

${ }^{\mathrm{c}}$ Delay between date of hospital appointment and date of diagnosis.

${ }^{\mathrm{d}}$ Delay between date of diagnosis and multidisciplinary meeting date.

${ }^{\mathrm{e}}$ Delay between date of diagnosis and admission for surgery.

${ }^{\mathrm{f}}$ Delay between referral based on symptoms and date of the first surgical procedure or treatment (total delay).

\section{Sensitivity Analyses}

There was good concordance between all models except for the effect of diagnostic delays on survival in patients with rectal cancer. A borderline result was obtained when censored patients were excluded $(P=.052)$. Neither stratifying the models by cancer stage nor excluding covariates related to cancer behavior substantively altered the results. The results of the sensitivity analyses are shown in Table 4.

Table 4. Results of the sensitivity analyses.

\begin{tabular}{lcc}
\hline Types of sensitivity analyses and delays & Patients with colon cancer $(P$ value $)$ & Patients with rectal cancer $(P$ value $)$ \\
\hline Sensitivity analysis 1: Excludes patients & who do not have either a known follow-up date or date of death \\
Diagnostic delay & .10 & .05 \\
Treatment delay & .09 & .34 \\
Sensitivity analysis 2: Stratifies colon and rectal cancer cohorts by cancer stage & $.01^{\mathrm{a}}$ \\
Diagnostic delay & .24 & .72 \\
Treatment delay & .12 & $.03^{\mathrm{b}}$ \\
Sensitivity analysis 3: Repeats analyses after excluding tumor stage and grade & .58 \\
Diagnostic delay & .64 & .70
\end{tabular}

${ }^{a}$ The statistically significant relationship between diagnostic delay and survival in the rectal cancer cohort remained consistent when stratifying by cancer stage, where the first quartile group was significantly less likely to die than the fourth quartile group (hazard ratio $0.141,95 \%$ CI $0.034-0.590$; $P=.01)$.

${ }^{\mathrm{b}}$ When excluding tumor grade and stage, patients with the shortest delays were significantly less likely to die than those with the longest delays (hazard ratio $0.165,95 \%$ CI $0.044-0.616, P=.03)$.

\section{Discussion}

\section{Summary and Interpretation of Findings}

This observational study investigated the relationship between health care provider delays and survival of patients with CRC. The median diagnostic delays were 34 days for both cancer types, while the median treatment delays for the patients with colon cancer and rectal cancer were 31 and 42 days, respectively. Contrary to the stated hypothesis, the health care provider delays had no effect on survival in this cohort.
Although longer diagnostic delays were associated with worse survival in the rectal cancer cohort, this relationship was statistically nonsignificant when restricting the analysis to patients with a known follow-up date or date of death. Further, although it is necessary to censor the patients who emigrate, are lost to follow-up, or for whom no date of death is recorded but who have not yet had a follow-up appointment, the nonsignificant result in this model may indicate that a disproportionately greater number of patients with shorter diagnostic delays were censored in the initial analysis. 
Considering this limitation, any conclusion regarding diagnostic delays in the rectal cancer cohort should be made tentatively.

Nonetheless, analysis of the delay subdivisions indicated that the delay between the first hospital appointment and diagnosis significantly affects survival. This may suggest that the effect on outcomes is due to unmeasured confounders relating to the nature of a patient's diagnostic pathway. For example, frail patients may receive a computed tomography colonoscopy prior to an endoscopic procedure. These patients could experience longer diagnostic delays but are more likely to die. Future research should therefore adjust for the nature of the diagnostic testing performed, as this may confound the diagnostic interval and survival, thereby creating a spurious positive correlation between diagnostic delay and risk of death [12,13].

Previous studies have shown longer diagnostic delays in patients with colon cancer [38,39], which have been attributed to the symptoms being presented vaguely [40]. However, median diagnostic delays were the same for both cancers in this study. This may indicate a more homogenous group regarding presenting symptoms. Treatment delays were longer for patients with rectal cancer, and this is likely due to the higher incidence of neoadjuvant therapy [41], which requires oncological referral.

Risk of death increases for each stepwise progression in the cancer stage $[42,43]$ and as expected, tumor stage was a significant predictor of survival in most models. Similarly, tumor grade was a significant covariate in many models; however, often with a smaller effect in increasing the hazard ratio of death. This may be due to the relative inconsequence of tumor grade in early-stage CRC. O'Connell et al [43] investigated the effect of tumor grade on survival by cancer stage and found a significant relationship between grade and survival in TNM stages II to IV but not stage I.

Previous literature has produced mixed results regarding the association between diagnostic delay and tumor stage. Ramos et al [44] found that delay was not significantly correlated with tumor stage. This finding was corroborated by several other researchers $[45,46]$ — though not all the previous studies — with some researchers finding an inverse association between diagnostic delay and tumor stage [14,24,38]. Our study demonstrates no significant relationship between tumor stage and health care provider delays, contending the previously held notion that tumor stage is an intermediate factor between delay and survival [13].

\section{Comparison of the Main Findings with Previous Works}

The paucity of evidence for a relationship between delay and survival in this study supports the results of previously published studies [22,47,48]. In a 2007 systematic review, 20 of the 26 studies found no association between delays and survival of patients with CRC [49]. Four studies found that longer delays were associated with favorable prognoses, with only 2 studies demonstrating an inverse relationship with worse outcomes. Studies that reported that longer delays lead to favorable outcomes likely fail to account for tumor aggressiveness either by restricting analysis to nonemergent cases [18] or by accounting for the confounding factor of the tumor grade $[44,49]$.
There have also been various approaches to data analysis in this field. In a general practitioner-based study of 268 patients, a Danish group treated diagnostic delay as a continuous variable and conducted a restricted cubic spline regression analysis. This analysis revealed that patients who experienced $>5$ weeks of delay had a greater risk of death [13]. The study collected delay data retrospectively, making recall and information bias difficult to avoid. Additionally, they were unable to account for the tumor grade and considered colon and rectal cancers together.

A subsequent study of 958 patients with CRC by Murchie et al [35] also used restricted cubic spline regression analysis, which was adjusted for grade, symptoms, emergencies, and place of presentation. Furthermore, they used registry data and explored the relationship between delay and survival separately for colon and rectal cancers. They found no association between health care provider delay and the survival of patients with CRC.

Such conflicting results indicate that the relationship between health care provider delay and survival of patients with CRC remains uncertain [18] — an issue compounded by the ethical limitations of conducting a randomized control trial. Despite this, the evidence against the influence of delay on survival has remained consistent. However, it is important to note that median delays of 31-42 days for diagnosis and treatment in this study represented a relatively short period of time. It was therefore not possible to investigate the effect of lengthy delays on the survival of patients with CRC. Future research in settings wherein it is possible to measure the diagnostic delay from a patient's subjective experience of symptoms or in areas with longer treatment delays may capture a relationship in the context of extended delays and survival.

Few studies have explored the effect of delays on postoperative outcomes such as readmission or complication rates. Psychosocial factors such as quality of life and anxiety are seldom assessed. Such outcomes should increasingly become the focus of future research.

\section{Context of the Findings}

Timeliness and quality are not necessarily congruent and expediting the care of patients may be detrimental in certain circumstances. For example, McConnell et al [50] found that patients with CRC achieving a 4-week benchmark between diagnosis and surgery were less likely to have had preoperative staging. Although longer delays are undesirable, the 2-week wait pathway has not appreciably improved the outcomes and has increased the wait times for routine referrals, which remains the most common pathway for CRC diagnosis [51]. However, there is evidence that diagnosing CRC prior to symptom onset considerably improves survival. Annual occult blood tests reduce the 13 -year cumulative mortality by $33 \%$ [52], and a single screening by sigmoidoscopy achieves similar results [53]. Public health initiatives should focus on improving compliance with screening programs, wherein prompt intervention improves outcomes.

\section{Strengths and Limitations}

The Kaplan-Meier and Cox regression methods assume that censoring is independent of a patient's risk of death. This may not have been the case, given the change in the significance 
between diagnostic delay and survival in the sensitivity analysis, which excluded censored patients. This suggests that the initial model underestimated the survival of patients with the shortest delays. However, others utilizing this technique have found the opposite, with censored patients being less likely to die, and therefore may have overestimated mortality in their analyses $[12,54,55]$. The magnitude and direction of this bias is therefore difficult to predict.

It was not possible to consider the initial presenting symptoms in this study. However, rectal bleeding has been associated with both poor [45] and improved [22] outcomes. Pruitt et al [14] stratified their cohort into 4 groups representing common presenting symptoms and found that this made no difference to their results. The effect of symptoms on survival is likely mediated by the cancer stage, which has been controlled for in this study.

There were also limitations associated with utilizing registry data. First, an analysis of patient delay was not possible, which is defined as the time between a patient noticing symptoms and presenting these symptoms to the general practitioner. However, patient delay data is often accrued through interviews or questionnaires, making recall bias difficult to avoid [18]. Even in prospective studies utilizing a structured interview format, there is often disagreement between patient responses and the clinical history [56,57]. Conclusions regarding patient delays should therefore be made cautiously. Secondly, survival should ideally be measured from the date of the first symptom presentation for diagnostic delay analysis [58,59]; however, this was not recorded in the Somerset Cancer Register. Finally, there was a short mean follow-up period of survival in this study, indicating that the conclusions are most relevant to 1-year survival rates. Continued follow-up of patients would allow for 5-year and 10-year survival trends to be analyzed in the future.

Despite these limitations, this study has several strengths. Registry data was entered synchronously with clinical practice, making this analysis resilient to recall bias [18]. Utilizing a population-based sample not restricted to those in tertiary care ensures more generalizable results. Unlike many previous studies, tumor aggressiveness and emergencies were controlled for, thereby minimizing the wait-time paradox. This study adjusted for several important biases and considered patients with colon cancer and rectal cancer separately. The Somerset Cancer Register data allowed an analysis of delay subdivisions, which ensured that important trends were not subsumed in a monotonic or a dichotomized delay model, while allowing clinically relevant conclusions about delays and their causes to be made. Finally, sensitivity analyses ensured the internal validity of the results.

\section{Conclusion}

This observational study investigated the effect of health care delays on survival in patients with CRC. It is reasonable to conclude that the relatively short health care provider delays experienced by patients in the United Kingdom are not likely to affect the outcomes. Promoting effective screening programs should remain a high public health priority.

\section{Authors' Contributions}

AA was involved in data acquisition, study design, statistical analysis, and write-up of this manuscript. CA was involved in data acquisition, preprocessing, and a full review of the work. PZ was involved in the study design and many of the research study's conclusions.

\section{Conflicts of Interest}

None declared.

\section{References}

1. Cancer Research UK. Bowel cancer statistics, Cancer Research UK (2018). Cancer Research UK. 2018 Jan 01. URL: https:/ /www.cancerresearchuk.org/about-cancer/bowel-cancer/about-bowel-cancer [accessed 2019-08-17]

2. Berrino F, De Angelis R, Sant M, Rosso S, Bielska-Lasota M, Lasota MB, EUROCARE Working group. Survival for eight major cancers and all cancers combined for European adults diagnosed in 1995-99: results of the EUROCARE-4 study. Lancet Oncol 2007 Sep 01;8(9):773-783. [doi: 10.1016/S1470-2045(07)70245-0] [Medline: 17714991]

3. Abdel-Rahman M, Stockton D, Rachet B, Hakulinen T, Coleman MP. What if cancer survival in Britain were the same as in Europe: how many deaths are avoidable? Br J Cancer 2009 Dec 03;101 Suppl 2:S115-S124 [FREE Full text] [doi: 10.1038/sj.bjc.6605401] [Medline: 19956155]

4. Nelson H, Petrelli N, Carlin A, Couture J, Fleshman J, Guillem J, National Cancer Institute Expert Panel. Guidelines 2000 for colon and rectal cancer surgery. J Natl Cancer Inst 2001 Apr 18;93(8):583-596. [doi: 10.1093/jnci/93.8.583] [Medline: 11309435]

5. Gatta G, Capocaccia R, Sant M, Bell CM, Coebergh JW, Damhuis RA, et al. Understanding variations in survival for colorectal cancer in Europe: a EUROCARE high resolution study. Gut 2000 Oct 01;47(4):533-538 [FREE Full text] [doi: 10.1136/gut.47.4.533] [Medline: 10986214]

6. McPhail S, Elliss-Brookes L, Shelton J, Ives A, Greenslade M, Vernon S, et al. Emergency presentation of cancer and short-term mortality. Br J Cancer 2013 Oct 15;109(8):2027-2034 [FREE Full text] [doi: 10.1038/bjc.2013.569] [Medline: 24045658] 
7. Elliss-Brookes L, McPhail S, Ives A, Greenslade M, Shelton J, Hiom S, et al. Routes to diagnosis for cancer - determining the patient journey using multiple routine data sets. Br J Cancer 2012 Oct 09;107(8):1220-1226 [FREE Full text] [doi: 10.1038/bjc.2012.408] [Medline: 22996611]

8. Coleman MP, Forman D, Bryant H, Butler J, Rachet B, Maringe C, ICBP Module 1 Working Group. Cancer survival in Australia, Canada, Denmark, Norway, Sweden, and the UK, 1995-2007 (the International Cancer Benchmarking Partnership): an analysis of population-based cancer registry data. Lancet 2011 Jan 08;377(9760):127-138 [FREE Full text] [doi: 10.1016/S0140-6736(10)62231-3] [Medline: 21183212]

9. Thomson CS, Forman D. Cancer survival in England and the influence of early diagnosis: what can we learn from recent EUROCARE results? Br J Cancer 2009 Dec 03;101 Suppl 2:S102-S109 [FREE Full text] [doi: 10.1038/sj.bjc.6605399] [Medline: 19956153]

10. Fisher DA, Zullig LL, Grambow SC, Abbott DH, Sandler RS, Fletcher RH, et al. Determinants of medical system delay in the diagnosis of colorectal cancer within the Veteran Affairs Health System. Dig Dis Sci 2010 May 01;55(5):1434-1441 [FREE Full text] [doi: 10.1007/s10620-010-1174-9] [Medline: 20238248]

11. Auvinen A. Social class and colon cancer survival in Finland. Cancer 1992 Jun 15;70(2):402-409. [doi: 10.1002/1097-0142(19920715)70:2<402::aid-cncr2820700206>3.0.co;2-p] [Medline: 1617590]

12. Tørring ML, Frydenberg M, Hamilton W, Hansen RP, Lautrup MD, Vedsted P. Diagnostic interval and mortality in colorectal cancer: U-shaped association demonstrated for three different datasets. J Clin Epidemiol 2012 Jun 01;65(6):669-678. [doi: 10.1016/i.jclinepi.2011.12.006] [Medline: 22459430]

13. Tørring ML, Frydenberg M, Hansen RP, Olesen F, Hamilton W, Vedsted P. Time to diagnosis and mortality in colorectal cancer: a cohort study in primary care. Br J Cancer 2011 Mar 15;104(6):934-940 [FREE Full text] [doi: 10.1038/bjc.2011.60] [Medline: 21364593]

14. Pruitt SL, Harzke AJ, Davidson NO, Schootman M. Do diagnostic and treatment delays for colorectal cancer increase risk of death. Cancer Causes Control 2013 May 01;24(5):961-977 [FREE Full text] [doi: 10.1007/s10552-013-0172-6] [Medline: 23446843]

15. NHS, The Somerset Cancer Register. Developed by the NHS for the NHS. URL: https://www.somersetscr.nhs.uk/ about-the-scr/ [accessed 2016-03-16]

16. Ella Ohuma, Nick Ormiston-Smith, Emily Power, Jodie Moffat, Catherine S Thomson. Update on the evaluation of the 53 local NAEDI projects targeting the earlier diagnosis of breast, bowel and lung cancers. Update on the evaluation of the 53 local NAEDI projects targeting the earlier diagnosis of breast, bowel and lung cancers. 2012 Jan 01. URL: https://www. cancerresearchuk.org/sites/default/files/update on the evaluation of the 53 local naedi projects.pdf [accessed 2020-06-19]

17. Wagner JS, Adson MA, Van Heerden JA, Adson MH, Ilstrup DM. The natural history of hepatic metastases from colorectal cancer. A comparison with resective treatment. Ann Surg 1984 May 01;199(5):502-508. [doi: 10.1097/00000658-198405000-00002] [Medline: 6721600]

18. Neal RD. Do diagnostic delays in cancer matter? Br J Cancer 2009 Dec 03;101 Suppl 2:S9-S12 [FREE Full text] [doi: 10.1038/sj.bjc.6605384] [Medline: 19956171]

19. Rupassara KS, Ponnusamy S, Withanage N, Milewski PJ. A paradox explained? Patients with delayed diagnosis of symptomatic colorectal cancer have good prognosis. Colorectal Dis 2006 Jun 01;8(5):423-429. [doi: 10.1111/j.1463-1318.2006.00958.x] [Medline: 16684087 ]

20. Munkholm P. Review article: the incidence and prevalence of colorectal cancer in inflammatory bowel disease. Aliment Pharmacol Ther 2003 Sep 01;18 Suppl 2:1-5. [doi: 10.1046/j.1365-2036.18.s2.2.x] [Medline: 12950413]

21. McArdle CS, Hole DJ. Emergency presentation of colorectal cancer is associated with poor 5-year survival. Br J Surg 2004 May 01;91(5):605-609. [doi: 10.1002/bjs.4456] [Medline: 15122613]

22. Stapley S, Peters TJ, Sharp D, Hamilton W. The mortality of colorectal cancer in relation to the initial symptom at presentation to primary care and to the duration of symptoms: a cohort study using medical records. Br J Cancer 2006 Nov 20;95(10):1321-1325 [FREE Full text] [doi: 10.1038/sj.bjc.6603439] [Medline: 17060933]

23. Iversen LH, Antonsen S, Laurberg S, Lautrup MD. Therapeutic delay reduces survival of rectal cancer but not of colonic cancer. Br J Surg 2009 Oct 01;96(10):1183-1189. [doi: 10.1002/bjs.6700] [Medline: 19787765]

24. Jullumstrø E, Lydersen S, Møller B, Dahl O, Edna T. Duration of symptoms, stage at diagnosis and relative survival in colon and rectal cancer. Eur J Cancer 2009 Sep;45(13):2383-2390. [doi: 10.1016/j.ejca.2009.03.014] [Medline: 19356923]

25. Feinleib M, Zelen M. Some pitfalls in the evaluation of screening programs. Arch Environ Health 1969 Sep;19(3):412-415. [doi: 10.1080/00039896.1969.10666863] [Medline: 5807744]

26. Coates AS. Breast cancer: delays, dilemmas, and delusions. Lancet 1999 Apr 03;353(9159):1112-1113. [doi: 10.1016/S0140-6736(99)00082-3] [Medline: 10209969]

27. Dragsted L, Jörgensen J, Jensen NH, Bönsing E, Jacobsen E, Knaus WA, et al. Interhospital comparisons of patient outcome from intensive care: importance of lead-time bias. Crit Care Med 1989 May;17(5):418-422. [doi:

10.1097/00003246-198905000-00008] [Medline: 2707011]

28. Duffy SW, Nagtegaal ID, Wallis M, Cafferty FH, Houssami N, Warwick J, et al. Correcting for lead time and length bias in estimating the effect of screen detection on cancer survival. Am J Epidemiol 2008 Jul 01;168(1):98-104. [doi: 10.1093/aje/kwn120] [Medline: 18504245] 
29. Day NE, Walter SD. Simplified models of screening for chronic disease: estimation procedures from mass screening programmes. Biometrics 1984 Mar;40(1):1-14. [Medline: 6733223]

30. Brenner H, Altenhofen L, Katalinic A, Lansdorp-Vogelaar I, Hoffmeister M. Sojourn time of preclinical colorectal cancer by sex and age: estimates from the German national screening colonoscopy database. Am J Epidemiol 2011 Nov 15;174(10):1140-1146. [doi: 10.1093/aje/kwr188] [Medline: 21984657]

31. Suissa S. Immortal time bias in pharmaco-epidemiology. Am J Epidemiol 2008 Feb 15;167(4):492-499. [doi: 10.1093/aje/kwm324] [Medline: 18056625]

32. Suissa S. Immortal time bias in observational studies of drug effects. Pharmacoepidemiol Drug Saf 2007 Mar;16(3):241-249. [doi: $10.1002 /$ pds.1357] [Medline: 17252614]

33. Walter F, Webster A, Scott S, Emery J. The Andersen Model of Total Patient Delay: a systematic review of its application in cancer diagnosis. J Health Serv Res Policy 2012 Apr;17(2):110-118 [FREE Full text] [doi: 10.1258/jhsrp.2011.010113] [Medline: 22008712]

34. Sørensen JB, Klee M, Palshof T, Hansen HH. Performance status assessment in cancer patients. An inter-observer variability study. Br J Cancer 1993 Apr;67(4):773-775 [ㅌEE Full text] [doi: 10.1038/bjc.1993.140] [Medline: $\underline{8471434]}$

35. Murchie P, Raja EA, Brewster DH, Campbell NC, Ritchie LD, Robertson R, et al. Time from first presentation in primary care to treatment of symptomatic colorectal cancer: effect on disease stage and survival. Br J Cancer 2014 Jul 29;111(3):461-469 [FREE Full text] [doi: 10.1038/bjc.2014.352] [Medline: 24992583]

36. Lakoff J, Paszat LF, Saskin R, Rabeneck L. Risk of developing proximal versus distal colorectal cancer after a negative colonoscopy: a population-based study. Clin Gastroenterol Hepatol 2008 Oct;6(10):1117-21; quiz 1064. [doi: 10.1016/j.cgh.2008.05.016] [Medline: 18691942]

37. Caplin S, Cerottini JP, Bosman FT, Constanda MT, Givel JC. For patients with Dukes' B (TNM Stage II) colorectal carcinoma, examination of six or fewer lymph nodes is related to poor prognosis. Cancer 1998 Aug 15;83(4):666-672. [Medline: 9708929]

38. Wattacheril J, Kramer JR, Richardson P, Havemann BD, Green LK, Le A, et al. Lagtimes in diagnosis and treatment of colorectal cancer: determinants and association with cancer stage and survival. Aliment Pharmacol Ther 2008 Nov 01;28(9):1166-1174 [FREE Full text] [doi: 10.1111/j.1365-2036.2008.03826.x] [Medline: 18691351]

39. Bilimoria KY, Ko CY, Tomlinson JS, Stewart AK, Talamonti MS, Hynes DL, et al. Wait times for cancer surgery in the United States: trends and predictors of delays. Ann Surg 2011 Apr;253(4):779-785. [doi: 10.1097/SLA.0b013e318211cc0f] [Medline: 21475020]

40. Korsgaard M, Pedersen L, Sørensen HT, Laurberg S. Reported symptoms, diagnostic delay and stage of colorectal cancer: a population-based study in Denmark. Colorectal Dis 2006 Oct;8(8):688-695. [doi: 10.1111/j.1463-1318.2006.01014.x] [Medline: 16970580$]$

41. Jiang DM, Raissouni S, Mercer J, Kumar A, Goodwin R, Heng DY, et al. Clinical outcomes of elderly patients receiving neoadjuvant chemoradiation for locally advanced rectal cancer. Ann Oncol 2015 Oct;26(10):2102-2106 [FREE Full text] [doi: 10.1093/annonc/mdv331] [Medline: 26232491]

42. Marcella S, Miller JE. Racial differences in colorectal cancer mortality. The importance of stage and socioeconomic status. J Clin Epidemiol 2001 Apr;54(4):359-366. [doi: 10.1016/s0895-4356(00)00316-4] [Medline: 11297886]

43. O'Connell JB, Maggard MA, Ko CY. Colon cancer survival rates with the new American Joint Committee on Cancer sixth edition staging. J Natl Cancer Inst 2004 Oct 06;96(19):1420-1425. [doi: 10.1093/jnci/djh275] [Medline: 15467030]

44. Ramos M, Esteva M, Cabeza E, Llobera J, Ruiz A. Lack of association between diagnostic and therapeutic delay and stage of colorectal cancer. Eur J Cancer 2008 Mar;44(4):510-521. [doi: 10.1016/j.ejca.2008.01.011] [Medline: 18272362]

45. Terhaar sive Droste JS, Oort FA, van der Hulst RWM, Coupé VMH, Craanen ME, Meijer GA, et al. Does delay in diagnosing colorectal cancer in symptomatic patients affect tumor stage and survival? A population-based observational study. BMC Cancer 2010 Jun 28;10:332 [FREE Full text] [doi: 10.1186/1471-2407-10-332] [Medline: 20584274]

46. Porta M, Fernandez E, Alguacil J. Semiology, proteomics, and the early detection of symptomatic cancer. J Clin Epidemiol 2003 Sep;56(9):815-819. [doi: 10.1016/s0895-4356(03)00165-3] [Medline: 14505764]

47. Ponz de Leon M, Sant M, Micheli A, Sacchetti C, Di Gregorio C, Fante R, et al. Clinical and pathologic prognostic indicators in colorectal cancer. A population-based study. Cancer 1992 Feb 01;69(3):626-635. [doi: 10.1002/1097-0142(19920201)69:3<626::aid-cncr2820690305>3.0.co;2-\#] [Medline: 1730115]

48. Fernandez E, Porta M, Malats N, Belloc J, Gallén M. Symptom-to-diagnosis interval and survival in cancers of the digestive tract. Dig Dis Sci 2002 Nov;47(11):2434-2440. [doi: 10.1023/a:1020535304670] [Medline: 12452375]

49. Ramos M, Esteva M, Cabeza E, Campillo C, Llobera J, Aguiló A. Relationship of diagnostic and therapeutic delay with survival in colorectal cancer: a review. Eur J Cancer 2007 Nov;43(17):2467-2478. [doi: 10.1016/j.ejca.2007.08.023] [Medline: 17931854]

50. McConnell YJ, Inglis K, Porter GA. Timely access and quality of care in colorectal cancer: are they related? Int J Qual Health Care 2010 Jun;22(3):219-228. [doi: 10.1093/intqhc/mzq010] [Medline: 20207714]

51. Rai S, Kelly MJ. Prioritization of colorectal referrals: a review of the 2-week wait referral system. Colorectal Dis 2007 Mar;9(3):195-202. [doi: 10.1111/j.1463-1318.2006.01107.x] [Medline: 17298615] 
52. Mandel JS, Bond JH, Church TR, Snover DC, Bradley GM, Schuman LM, et al. Reducing mortality from colorectal cancer by screening for fecal occult blood. Minnesota Colon Cancer Control Study. N Engl J Med 1993 May 13;328(19):1365-1371. [doi: 10.1056/NEJM199305133281901] [Medline: $\underline{8474513}$ ]

53. Selby JV, Friedman GD, Quesenberry CP, Weiss NS. A case-control study of screening sigmoidoscopy and mortality from colorectal cancer. N Engl J Med 1992 Mar 05;326(10):653-657. [doi: 10.1056/NEJM199203053261001] [Medline: 1736103]

54. Stapley S, Peters TJ, Sharp D, Hamilton W. The mortality of colorectal cancer in relation to the initial symptom at presentation to primary care and to the duration of symptoms: a cohort study using medical records. Br J Cancer 2006 Nov 20;95(10):1321-1325 [FREE Full text] [doi: 10.1038/sj.bjc.6603439] [Medline: 17060933]

55. Hamilton W, Round A, Sharp D, Peters TJ. Clinical features of colorectal cancer before diagnosis: a population-based case-control study. Br J Cancer 2005 Aug 22;93(4):399-405 [FREE Full text] [doi: 10.1038/sj.bjc.6602714] [Medline: 16106247]

56. Gonzalez-Hermoso F, Perez-Palma J, Marchena-Gomez J, Lorenzo-Rocha N, Medina-Arana V. Can early diagnosis of symptomatic colorectal cancer improve the prognosis? World J Surg 2004 Jul;28(7):716-720. [doi: 10.1007/s00268-004-7232-8] [Medline: 15383871]

57. Roncoroni L, Pietra N, Violi V, Sarli L, Choua O, Peracchia A. Delay in the diagnosis and outcome of colorectal cancer: a prospective study. Eur J Surg Oncol 1999 Apr;25(2):173-178. [doi: 10.1053/ejso.1998.0622] [Medline: 10218461]

58. Coates AS. Breast cancer: delays, dilemmas, and delusions. Lancet 1999 Apr 03;353(9159):1112-1113. [doi: 10.1016/S0140-6736(99)00082-3] [Medline: 10209969]

59. Richards MA, Westcombe AM, Love SB, Littlejohns P, Ramirez AJ. Influence of delay on survival in patients with breast cancer: a systematic review. Lancet 1999 Apr 03;353(9159):1119-1126. [doi: 10.1016/s0140-6736(99)02143-1] [Medline: $\underline{10209974]}$

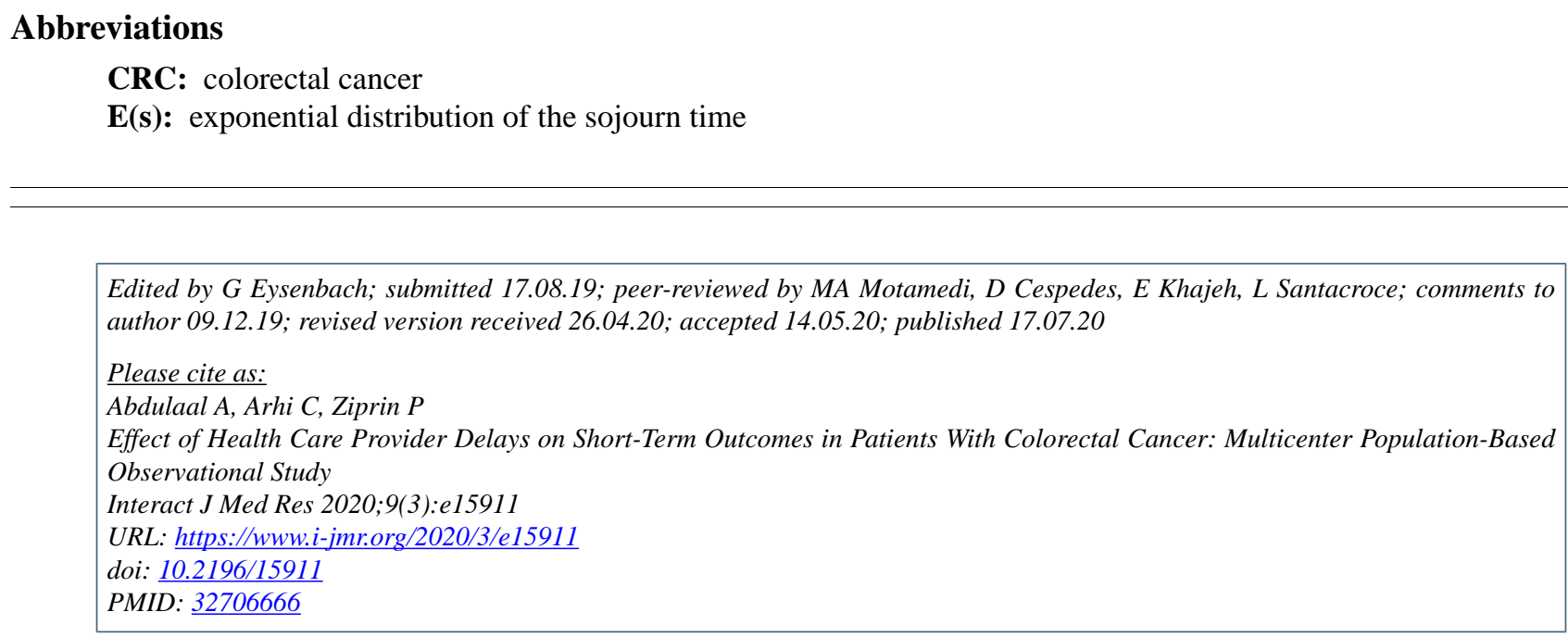

(C)Ahmed Abdulaal, Chanpreet Arhi, Paul Ziprin. Originally published in the Interactive Journal of Medical Research (http://www.i-jmr.org/), 17.07.2020. This is an open-access article distributed under the terms of the Creative Commons Attribution License (https://creativecommons.org/licenses/by/4.0/), which permits unrestricted use, distribution, and reproduction in any medium, provided the original work, first published in the Interactive Journal of Medical Research, is properly cited. The complete bibliographic information, a link to the original publication on http://www.i-jmr.org/, as well as this copyright and license information must be included. 